doi: $10.12957 /$ childphilo.2020.48213

\title{
a formação continuada e a experiência ética do corpo na produção do currículo
}

\section{da educação infantil}

sammy lopes ${ }^{1}$

universidade do estado do rio de janeiro, brasil orcid id: https:/ / orcid.org/0000-0002-6017-5844

\section{resumo}

O trabalho aborda o problema da formação continuada das professoras na educação infantil na contemporaneidade, perguntando como elaborar percursos formativos que não se pautem exclusivamente nos modelos/padrões de profissionalização predeterminados pela produção acadêmica, e posteriormente adotados pelas políticas de governo. Se organiza a partir do movimento investigativo traçado com as professoras que participam do projeto de extensão e pesquisa UERJ-EDU-DEDI, coordenado pelo autor. Analisa criticamente as principais causas que justificam o fracasso dos projetos de formação instituídos com base nos citados modelos de profissionalização e aponta possibilidades conceituais para se pensar processos formativos mais imanentes, isto é, produzidos a partir das experiências que se desenrolam no próprio movimento curricular, experiências nas quais as professoras tentam construir relações educadoras mais éticas com a infância. Conclui que o movimento formador precisa se configurar como espaço-tempo para a expressão e avaliação coletiva das potencialidades ético-educativas engendradas nessas experiências. $O$ trabalho se alinha conceitualmente à filosofia da diferença de Gilles Deleuze, sobretudo à leitura que realiza da "Ética" de Baruch Spinoza. Orienta-se metodologicamente pelo acompanhamento das cartografias dos modos de subjetivação traçados pelas professoras no processo de produção dos currículos para educação infantil, segundo o norteamento teórico fornecido por Suely Rolnik e Felix Guattari.

palavras-chave: educação infantil; currículo; formação continuada; experiência; cuidado de si.

\section{a formação continuada e a experiência ética do corpo na produção do currículo da educação infantil}

\section{abstract}

The paper addresses the problem of continuing education of teachers in early childhood education in contemporary times, asking how to elaborate formative pathways that do not focus exclusively on the models/standards of professionalization predetermined by academic production, and later adopted by government policies. It is organized from the investigative movement traced with the teachers who participate in the extension-research project UERJ-EDU-DEDI, coordinated by the author. It critically analyzes the main causes that justify the failure of the training projects established based on the aforementioned models of professionalization and points out conceptual possibilities to think more immanent formative processes, that is, produced from the experiences that unfold itself in the curricular movement, experiences in which teachers try to build more ethical educational relationships with childhood. It concludes that the formative movement needs to be configured as space-time for the expression and collective evaluation of the ethicaleducational potentialities engendered in these experiences. The work is conceptually aligned with Gilles Deleuze's philosophy of difference, especially the reading he performs

1 E-mail: samwlopes@gmail.com 
a formação continuada e a experiência ética do corpo na produção do currículo da educação infantil

of Baruch Spinoza's "Ethics". It is methodologically guided by the monitoring the modes of subjectivation cartography traced by the teachers in the process of curriculum production for early childhood education, according to the theoretical guidance provided by Suely Rolnik and Felix Guattari.

keywords: early childhood education; curriculum; continuing education; experience; selfcare.

\section{a formação continuada e a experiência ética do corpo na produção do currículo da educação infantil}

\section{resumen}

El trabajo aborda el problema de la educación continua de los maestros en la educación de la primera infancia en los tiempos contemporáneos, preguntando cómo elaborar vías formativas que no se centran exclusivamente en los modelos/estándares de profesionalización predeterminados por la producción académica, y más tarde adoptados por las políticas gubernamentales. Se organiza a partir del movimiento de investigación trazado con los profesores que participan en el proyecto de extensión e investigación UERJEDU-DEDI, coordinado por el autor. Analiza críticamente las principales causas que justifican el fracaso de los proyectos formativos establecidos a partir de los mencionados modelos de profesionalización y señala posibilidades conceptuales para pensar procesos formativos más inmanentes, es decir, producidos a partir de las experiencias que se desarrollan en el propio movimiento curricular, experiencias en las que los profesores tratan de construir relaciones educativas más éticas con la infancia. Concluye que el movimiento formativo debe configurarse como espacio-tiempo para la expresión y evaluación colectiva de las potencialidades ético-educativas que se generan en estas experiencias. La obra está conceptualmente alineada con la filosofía de diferencia de Gilles Deleuze, sobre todo con la lectura que hace de la "Ética" de Baruch Spinoza. Está orientado metodológicamente al monitorear las cartografías de los modos de subjetividad dibujados por los maestros en el proceso de producción de currículos para la educación de la primera infancia, de acuerdo con la orientación teórica proporcionada por Suely Rolnik y Felix Guattari.

palabras clave: educación infantil; currículo; formación continua; experiencia; autocuidado. 
a formação continuada e a experiência ética do corpo na produção do currículo da educação infantil

\section{1 crítica aos percursos de formação continuada de professoras baseados nos} modelos de profissionalização

Quando se pensa a formação de educadoras para a educação infantil a partir de uma perspectiva crítica e, ao mesmo tempo inventiva, é importante ponderar que em uma sociedade como a nossa, fortemente organizada com base na lógica do capital - na produção, no trabalho, na exploração e no consumo - as expectativas criadas em torno do problema da educação da infância e da formação de professoras tenderão a guiar-se sob a mesma lógica produtivista.

Dessa maneira, percebe-se que as políticas oficiais de formação continuada para as educadoras da infância estão submetidas a certos preceitos técnicoscientíficos os quais passam a definir os parâmetros de normalidade e do socialmente desejável para a organização e condução do processo formal de educação da infância, dedicado a efetuar a transformação da criança em um adulto útil ao sistema produtivo e, mais profundamente, a conservar o sonho de um futuro ideal para nossa sociedade burguesa e capitalista.

Percebe-se assim que os percursos de formação continuada de professoras para a educação infantil se instituem no âmbito de relações políticas muito complexas, nas quais tecnologias sutis de controle social tendem a se exercer sobre o corpo das educadoras; configurando-se como dispositivos para a conformação de determinados modos de subjetivação ${ }^{2}$ que normalizam certas imagens para nosso futuro sociopolítico, ao tempo mesmo em que excluem outras, discrepantes dos modelos instituídos. De modo que as relações que se traçam entre a formação técnica-científica e a formação sociopolítica e cultural da profissional docente da educação infantil se configuram como foco de especial interesse nas práticas de formação reguladas pelo Estado.

\footnotetext{
2 Os modos de subjetivação se referem aos processos (múltiplos e complexos) por meio dos quais atribuímos sentido ao mundo e à vida. São modos de ser, de pensar e de agir que recortam o tempoespaço concebendo regimes de signos, ao mesmo tempo interiores-exteriores, com os quais podemos (ainda que precariamente) desenhar certa imagem do real social. Dessa maneira, os modos de subjetivação estão diretamente implicados nas políticas de produção do desejo.
} 
a formação continuada e a experiência ética do corpo na produção do currículo da educação infantil

É comum se afirmar nos processos de formação continuada, por exemplo, o discurso que funda a imagem de uma sociedade educadora como uma espécie de modelo ideal para o progresso técnico-científico da nossa estrutura social. Mas nesses termos, usualmente, trata-se da imagem de uma sociedade educadora orientada sobremaneira à valorização dos padrões lógico-racionais constituídos, destacadamente, a partir do molde epistemológico clássico das ciências exatas.

Apreende-se assim porque os percursos de formação continuada de professoras, programados no âmbito do poder público - no que tange à sua concepção e modos de planejamento e implementação - se afirmam como uma modalidade de ação política forçada a desconsiderar o plano de imanência em que as professoras se constituem professoras, isto é, negar qualquer possibilidade de pensar os processos criativos que elas desenrolam no movimento curricular como acontecimento potencialmente formador. Recusando-se dessa forma o espaçotempo de produção das relações educadoras em que a atividade docente se compõe enquanto experiência vivida.

Tal postura, assumida de modo comumente pelas políticas públicas de formação continuada das professoras na educação infantil, além de colonizadora e autoritária; se configura como uma prática administrativa problemática: a tentativa de determinação do papel sociopolítico do profissional docente por forças externas ao processo educador - objetivando instituir a imagem ideal de um profissional "qualificado" e "competente" - acaba por produzir reações negativas quando do cumprimento em campo dos projetos de formação continuada, uma vez que, ao chegarem às escolas esses se mostram tendencialmente inócuos, artificiais e descontextualizados aos olhos das profissionais que lá se encontram, não atendendo às suas especificidades e expectativas formativas.

Frequentemente, as políticas de formação continuada instituídas pelo poder público - por conta da forma hierarquizada e autocrática como entendem o próprio sentido da formação; partem do mandatório de que para planejar e gerir o percurso formador é preciso imputar-lhe um caráter ortopédico; isto é, assumir como referência a imagem de um modelo ideal de profissionalização instituído por certas linhas sedentárias de produção acadêmica. Tal imagem ideal tende então a ser 
contraposta a uma imagem genérica e preconceituosa da prática educadora que, supostamente, se exerceria nas escolas, de modo que essa última possa, assim, ser classificada como deficitária ao não se alinhar ao modelo adotado.

Desse modo, o referido arquétipo da profissionalização fundamenta e guia a constituição e o desenvolvimento de uma modalidade de formação continuada comprometida essencialmente com o formato da capacitação e do treinamento. Trata-se de um empreendimento que precisará dotar as professoras com as qualidades teóricas e técnico-pragmáticas necessárias, as quais, de modo hipotético, lhes faltariam desde o início.

É comum também que as políticas oficiais de formação busquem implantar dispositivos de controle complementares, como os caráter meritocrático que visam adicionar ao processo formador ingredientes de natureza, dita, "motivadora". Para isso, são prometidas às escolas e às suas profissionais premiações de natureza diversa, vinculadas ao atingimento de metas preestabelecidas, de maneira a garantir que os preceitos reguladores prescritos sejam rigorosamente levados a cabo para se alcançar os resultados esperados. Explora-se dessa forma a cultura da competição e do individualismo como dispositivo formador que se efetua asseverando as relações de concorrência entre instituições educadoras e mesmo entre profissionais docentes em uma mesma unidade.

Na contramão do que se apontou anteriormente, destaca-se que os saberes e fazeres docentes elaborados no fluxo de produção das relações que engendram o ato de educar - em função da necessidade de enfrentar e dar respostas aos problemas concretos surgidos no movimento de constituição de tal fluxo; precisam ser necessariamente vinculados à dinâmica do processo formador, de modo a se provocar a afirmação do valor formativo potencial dos referidos saberes e fazeres, concebidos para dar corpo à experiência. Tal condição viabilizaria à professora a possibilidade de tentar enunciar ou atribuir sentidos diferenciais tanto ao ato de educar quanto à natureza da atividade docente.

Desse ponto de vista, os profissionais docentes da creche e a pré-escola pública não deveriam se tornar destinatários, por exemplo, do famigerado assédio moral que os coagem a se "modernizarem de modo permanente ", em função de 
a formação continuada e a experiência ética do corpo na produção do currículo da educação infantil

fazer frente às recorrentes crises paradigmáticas instauradas pelo capitalismo no intuito de impor as exigências de suas novas estratégias exploratórias. Tais assédios tentam forçar as professoras a reorientarem constantemente as suas ações a favor da atualização dos interesses contemporâneos do capital.

Percebe-se assim porque os percursos oficiais de formação continuada buscam apartar as professoras da possiblidade de pensar e atribuir problemas e sentidos singulares à educação e à sua própria profissionalidade, limitando os percursos de formação continuada na forma de dispositivos aptos a desenvolver um modo mais "autônomo e flexível" de atuação capaz de induzir o celebre "aprender a aprender": o capital precisa impor uma visão particularista e elitizada acerca do papel sociopolítico da educação e da profissão docente (o professor competente, o professor pesquisador, o professor reflexivo); ou seja, infligir visões de educação e de docência diretamente comprometidas com sua própria lógica de produção.

Nesse sentido, o discurso neoliberal dominante que influencia sobremaneira a elaboração das políticas públicas de formação continuada para as professoras da educação infantil, busca atribuir às docentes a versada "condição intratável de endividamento"; ou seja, caracterizá-las como sujeitos portadores de um débito formativo impagável: sob tal ponto de vista as professoras estariam como que condenadas a se reformularem indefinidamente, conforme a premissa de que o desenvolvimento profissional deve ocorrer de forma ininterrupta.

Nessa direção, enuncia-se o imperativo de que a formação deve...

[...] acompanhar a inovação e a evolução associadas ao conhecimento, à ciência e à tecnologia" [bem como desenvolver um] ...diálogo e a parceria com atores e instituições, capazes de contribuir para alavancar novos patamares de qualidade ao complexo trabalho de gestão da sala de aula e da escola. (Brasil, 2013, p. 11).

Busca-se regular os critérios de produção do sentido social da educação e do trabalho docente, impondo-se certas determinações conceituais e técnicas que, em última instância, visam conformar os modos de subjetivação da professora aos enquadres de um sujeito-objeto, resignado e diligente; ininterruptamente desejoso 


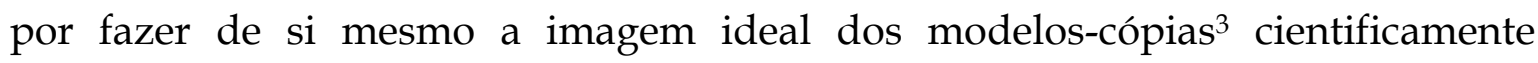
instituídos como aspiráveis.

Ainda que se enuncie em algumas proposições que a formação continuada precisará considerar...

[...] os problemas e os desafios da escola e do contexto onde ela está inserida... [reiterando-se que] ...o respeito ao protagonismo do professor e a um espaço-tempo [de formação] que lhe permita refletir criticamente e aperfeiçoar sua prática (Brasil, 2013, p. 11).

No que pese a aparente abertura sugerida no texto oficial - afiançando a possiblidade de se promover processos formativos mais abertos às demandas e experiências próprias das professoras; tais premissas serão rotineiramente traduzidas no desenrolar do percurso formador sob a ótica finalista da obtenção de resultados prefixados e da afirmação dos padrões de educação e profissionalização determinados exteriormente.

Pelo exposto, os movimentos intempestivos que compõem os planos de constituição da profissionalidade docente enquanto experiência imanente ao ato de educar, precisam ser como que subjugados à lógica colonial e racionalista dos percursos formativos; os quais tendem a assumir por princípio as imagens nas quais a professora é, senão a única, a principal responsável pelas situações de "sucesso" /"fracasso" dos educandos, induzindo a internalização dessas mesmas imagens de sucesso e fracasso para então associá-las à condição de eficiência ou ineficiência das práticas docentes.

Na contramão do exposto, o presente trabalho tentará produzir elementos teórico-práticos capazes afirmar a ação educadora da professora da educação infantil como experiência que se constitui potencialmente por meio de processos de produção de saberes e fazeres múltiplos e singulares. De modo que a profissionalidade docente, nessa perspectiva, se comporia não exclusivamente a partir da tentativa de reprodução de modelos de profissionalização pré-existentes,

\footnotetext{
3 A noção de simulacro em Platão, se impõe nos percursos oficiais de formação continuada: a imagem de docência a ser produzida é comumente idealizada como cópia que deve possuir um elevado grau de semelhança com o modelo instituído em instância (acadêmica) dita superior. Tal semelhança garantiria a necessária aproximação da cópia com tal modelo, de forma que para efetuar-se enquanto "boa cópia", a professora precisaria desenvolver a pretensão e capacidade necessárias para identificar-se, o melhor possível, com o modelo ideal de docência oferecido, buscando assumir seus critérios fundantes e dedicando a manter-se fiel à sua suposta originalidade.
} 
a formação continuada e a experiência ética do corpo na produção do currículo da educação infantil

mas também e de forma predominante, por artes de criação de estilos de ser professor que se engendram muito dinâmico no movimento instável de produção das relações educadoras que tecem o currículo; assumindo-se que tal movimento guarda em si, por natureza, uma ordem potencialmente formadora.

\section{2 o valor formativo da experiência}

Procurando assumir um ponto de vista de inflexão sobre o problema da formação continuada de professoras para a educação infantil, avesso à lógica dos modelos de profissionalização; contra argumenta-se que a formação pode e deve ser pensada a partir do próprio tempo-movimento em que as professoras se autorizam a vivenciar o encontro educativo enquanto experiência ética ${ }^{4}$ tecida com a infância, deixando-se afetar sensível e intelectualmente pelas diferenças que se engendram em tal experiência.

Sob tal aspecto, o problema da formação continuada alinhava-se de modo fundamental à questão da experiência, a qual se expressa como componente formativo essencial; ponto de partida e de chegada do artifício formador, passando a caracterizar o próprio sentido da formação.

Segundo Larrosa (2005, p. 51) a experiência se configura como “...uma viagem interior [e exterior] de autoconhecimento, de autodeterminação e de auto realização". A formação continuada baseada na experiência, manifesta-se, dessa forma, como modo de criação de um estilo dedicado a instigar a professora a expressar e afirmar certo desejo de autotransformação, imanente ao movimento em que ela, ocasionalmente, é forçada a acolher e manipular criativamente a diferença que emerge no encontro educativo com a infância ${ }^{5}$, rompendo assim com os modelos de profissionalização instaurados.

\footnotetext{
${ }^{4}$ Seguindo a abordagem de Deleuze (2004) sobre a ética do "cuidado de si" em Michel Foucault, esta consistiria em um conjunto de regras/normas de existência que os sujeitos impõem a si mesmos para promover certo estilo virtuoso de vida; isto é, uma estética da existência associada então a uma obra de arte. No cuidado de si o sujeito retorna sobre si mesmo para a produção de relações mais éticas com o mundo, consigo mesmo e com outrem.

5 Segundo Deleuze (2006, 2005, 1998, 1988-1989), a infância como processo se desenrola na temporalidade diferencial do devir-criança; ou seja, no acontecimento de irrupção do extraordinário no mundo. Nessa perspectiva, a infância extrapola a imagem cronológica, contínua e sucessiva do tempo, estendendo-se na afirmação da força produtiva da diferença. A infância se diz, portanto, no
} 
Entretanto, é preciso sublinhar que "auto", nesse caso, não diz respeito à...

[...] Individualidade de uma existência [dotada de uma consciência e identidade autocentradas] ..., mas à singularidade do modo como atravessam seu corpo as forças de um determinado contexto [sócio] histórico [cultural]. (Ronlik, 2006, p. 22).

Dessa forma, toma-se a experiência como um artifício potencialmente transformador, ou seja, como um campo de constituição para a elaboração de novas qualidades de aprender-ensinar e, consequentemente, de outros estilos de profissionalidade docente; isto é, tomar a experiência como processo em meio ao qual modos diferenciais de educar e de ser educador podem se esboçar e expressar potencialidades inovadoras.

A experiência se configura como um processo formador ao envolver um acontecimento, variação ou passagem de natureza afetiva que instaura, segundo Larrosa (2009, p. 19), “...a possibilidade de que algo nos aconteça ou nos toque.” De modo que, nesse sentido, a experiência sempre “...requer um gesto de interrupção" ou de ruptura com a ordem do que se apresenta instituído em termos de modelos/padrões/imagens ideais.

Em um contexto mais específico, a dinâmica caótica do movimento curricular na educação infantil (conformado nos processos de produção das relações educadoras) e os percursos de formação continuada precisam ser tomados como espaço-tempos necessariamente conexos e interdependentes, abertos à expressão das experiências, isto é, à possibilidade de enunciação da experiência pelo próprio sujeito da experiência.

Poderíamos, assim, tomar esse espaço-tempo conexo, que se estabelece entre o currículo 6 e o processo de formação como um verdadeiro...

[...] território de passagem, algo como uma superfície sensível que aquilo que acontece afeta de algum modo, produz alguns afetos, inscreve algumas marcas, deixa alguns vestígios, alguns efeitos... o

tempo-fluxo do processo de produção ou de desenvolvimento do referido devir... tomado enquanto possibilidade de concepção do ato de pensar no pensamento.

${ }^{6}$ Lopes (2011), caracteriza o currículo como processo ou movimento afetivo que se traça entre os corpos no nível de produção das relações educadoras, isto é, movimento/ processo em que o sentido do ato de aprender-ensinar se constitui sob o impulso da força da diferença. Desse ponto de vista o currículo se engendra na busca que se empreende para responder à questão: por que/como um corpo passa a desejar aprender-ensinar? Configurado em tal plano, o currículo alcança sua dimensão micropolítica. 
a formação continuada e a experiência ética do corpo na produção do currículo da educação infantil

sujeito da experiência é um ponto de chegada, um lugar a que chegam as coisas, como um lugar que recebe o que chega e que, ao receber, lhe dá lugar... [se] a experiência soa como "aquilo que nos acontece, nos sucede...o sujeito da experiência é sobretudo um espaço [tempo] onde têm lugar os acontecimentos. Em qualquer caso, seja como território de passagem, seja como lugar de chegada ou como espaço [tempo] do acontecer, o sujeito da experiência se define não [somente] por sua atividade, mas [também] por sua passividade, por sua receptividade, por sua disponibilidade, por sua abertura. Trata-se, porém, de uma passividade anterior à oposição entre ativo e passivo, de uma passividade feita de paixão, de padecimento, de paciência, de atenção, como uma receptividade primeira, como uma disponibilidade fundamental, como uma abertura essencial. (Larrosa, 2009, p.19).

Percebe-se dessa forma o quanto a conjunção entre o movimento curricular e a atividade de formação continuada pode (e deve) ser entendida como um plano de constituição para a expressão, reflexão/avaliação coletiva acerca das potencialidades das experiências traçadas entre o corpo docente e o corpo infante no trabalho educativo. Experiências nas quais a força da diferença necessariamente envolve e desenvolve-se, afetando sensivelmente a produção da relação educadora, forçando os corpos complicados no encontro a reverem seus territórios para tentar, ainda que ocasionalmente, elaborar novas possibilidades de ser em meio à produção do ato de aprender-ensinar.

Nesse contexto, afirma-se que...

O sujeito da experiência... é um sujeito alcançado, tombado, derrubado. Não um sujeito que permanece sempre em pé, ereto, erguido e seguro de si mesmo; não um sujeito que alcança aquilo que se propõe ou que se apodera daquilo que quer; não um sujeito definido por seus sucessos ou por seus poderes, mas um sujeito que perde seus poderes precisamente porque aquilo de que faz experiência (a diferença), dele se apodera. Em contrapartida, o sujeito da experiência é também um sujeito sofredor, padecente, receptivo, aceitante, interpelado, submetido. Seu contrário, o sujeito incapaz de experiência, seria um sujeito firme, forte, impávido, inatingível, erguido, anestesiado, apático, autodeterminado, definido por seu saber, por seu poder e por sua vontade. (Larrosa, 2009, p. 25). 
É justamente essa condição de desterritorialização ${ }^{7}$, imposta ao corpo pela experiência, isto é, pela diferença que a experiência porta, que melhor irá expressar o seu potencial valor formativo no contexto do currículo da educação infantil.

A experiência se apodera do corpo, desestabilizando os espaços-tempos do já sabido, forçando-o a pensar a si mesmo, mas, conforme a dessemelhança que o afeta. De modo que, seguindo Heidegger (1987), citado por Larrosa (2009, p. 25) "podemos ser assim transformados por tais experiências, de um dia para o outro ou no transcurso do tempo".

Avalia-se que o sujeito da experiência, coagido a desterritorializar-se ou a pensar o próprio corpo em função da diferença que o afeta - buscará, ao mesmo tempo, a operar sobre si certo processo de reterritorialização, o qual implicará sempre a inescapável reconfiguração dos territórios antes delineados.

Caso a professora consiga deixar fluir pelo corpo os afetos experimentados no encontro educativo com a infância (isto é, a diferença que tais afetos expressam); isso pode se configurar como uma condição de abertura essencial para a constituição do processo formador; uma vez que tal abertura viabilizaria a possibilidade de composição e afirmação de modos diferenciais de ação educadora, aptos a dar língua a novos estilos de pensar o sentido próprio da educação e da profissionalidade docente.

Assim, do ponto de vista de uma formação continuada voltada à experiência, o enlace entre o currículo e o próprio percurso formador desenrola-se, justamente no processo de...

[...] desmanchamento de certos mundos - sua perda de sentido - e [na] formação de outros: mundos que se criam para expressar afetos contemporâneos, em relação aos quais os universos [territórios] vigentes tornaram-se obsoletos. (Rolnik, 2006, p. 23).

Não por acaso Larrosa (2009, p. 25 - 26) afirma que um “...componente fundamental da experiência é sua capacidade de formação..."; isso ocorre em função de que é a passagem entre os movimentos de desterritorialização e

\footnotetext{
7 Conforme Rolnik (2006) a desterritorialização se caracteriza pelo abandono dos territórios existenciais socialmente instituídos (ideias, valores, culturas, tradições). Nesses territórios nos sentimos "em casa", seguros e protegidos pelo conforto do já sabido. Para desterritorializar-se, o pensamento precisa sair dos trilhos do habitual e desabrochar potencialmente como processo de criação de um novo.... rompendo com os territórios existentes, recriando-os... (reterritorialização).
} 
a formação continuada e a experiência ética do corpo na produção do currículo da educação infantil

reterritorialização, desencadeado pela força da experiência, que poderá a abrir o corpo a um abalo que o coage potencialmente a autotransformar-se. Pondera-se nesse sentido que se a experiência é...

[...] aquilo que "nos passa", ou que nos toca, ou que nos acontece, e ao nos passar nos forma e nos transforma. Somente o sujeito da [ou em movimento de] experiência está... aberto à sua própria (auto) transformação. (Larrosa, 2009, p. 26).

No entanto, a experiência não adquire por si só um valor formativo adequado - associado à capacidade de promover um espaço-tempo de autotransformação; se seu acontecimento não instiga o corpo da educadora a conformar novos modos de pensamento-ação que, para além de ultrapassar à ordem apaixonada dos encontros ${ }^{8}$, também sejam capazes de engendrar e afirmar possibilidades de se produzir relações educadoras mais éticas com a infância.

\section{3 ética e o cuidado de si na experiência da formação}

No contexto da educação infantil, a formação continuada pode ser pensada então como um movimento que busca acompanhar os modos de constituição e avaliar coletivamente as potencialidades dos distintos estilos de profissionalidade docente que se esboçam em meio ao processo de produção da experiência curricular. Experiência em que as docentes tentam compor a relação educadora com a infância e que pode destituir o adulto do seu usual território de poder, forçandoo a acolher e tratar de forma inventiva as diferenças que afloram no encontro com o corpo infante.

Nessa perspectiva, a formação continuada não se volta à instituição e reprodução de padrões predeterminados de profissionalidade docente, conformados pela expertise acadêmica. O problema da formação continuada se desloca para um plano outro de entendimento: deixamos de nos perguntar como forjar a imagem-modelo da professora ideal para discutir quais são as potências dos múltiplos estilos de profissionalidade docente esboçados na experiência curricular e como estes podem (ou não) se conceber e afirmar-se enquanto práticas educadoras mais ou menos éticas de composição com a infância; ou, em termos foucaultianos,

\footnotetext{
8 Segundo Deleuze (1992) a ordem apaixonada dos encontros diz respeito à formação de ideias inadequadas, conformadas de forma superficial e irrefletida, a partir das impressões primeiras produzidas pelos efeitos mais imediatos que afetam nosso corpo no encontro com o mundo.
} 
enquanto práticas de cuidado de si. Práticas nas quais se desenha “[...] uma certa forma de tomada de consciência de si mesmo, ou...uma certa forma de olhar que lançaremos sobre nós mesmos... [na busca pela dita autotransformação]" (Foucault, 2006, p. 579).

Ao se asseverar o potencial formador associado à noção de cuidado de si, tomada enquanto processo ético de auto-reflexão acerca dos modos de relação que estamos a constituir com outrem, sugere-se que o artifício de autotransformação que a experiência educadora tende a invocar, se potencializa nos currículos da educação infantil em função de que a professora...

[...]cuida de si em sua própria vida e de que a reputação que se vai deixar é o único além com o qual é possível se preocupar, o cuidado de si poderá então estar inteiramente centrado em si mesmo, naquilo que se faz, no lugar que se ocupa entre [/com] os outros... Ele poderá ser, ao mesmo tempo, senão um cuidado dos outros, pelo menos um cuidado de si [interdependente e] benéfico para os outros. (Foucault, 2004, p. 273).

Tal enfoque buscará acompanhar os processos de concepção dos diferentes modos de subjetivação que se enunciam na produção do sentido da profissionalidade docente (e do próprio ato de educar) no desenrolar do movimento curricular e do percurso formador, tomando tal movimento enquanto tempo-espaço essencial à efetuação de “[...] um exercício [ético possível] de si sobre si mesmo através do qual [a professora]... procura se elaborar, se transformar e atingir um certo modo [singular] de ser." (Foucault, 2004, p. 265).

Trata-se assim de um estilo intensivo de formação continuada, ou seja, de um estilo de intervenção formadora que se conforma no plano muito específico dos afetos $^{9}$ experimentados no acontecimento doencontro educativo. Um estilo de formação que se pergunta: que afetos a experiência educadora com a infância têm produzido no corpo das professoras? Como tais afetos tem conseguido (ou não)

\footnotetext{
${ }^{9}$ A partir dos efeitos que os corpos causam uns sobre os outros no encontro (afecções), o corpo tende a experienciar uma variação (para mais ou para menos) na sua capacidade atual de ser, agir e pensar em função das ideias que concebe sob a condução/influência de tais afecções. Assim, Deleuze (2002, p. 55). [...] de um estado a outro, de uma imagem ou ideia a outra, há... transições, passagens vivenciadas, durações mediante as quais passamos para uma perfeição maior ou menor. Ainda mais, esses estados, essas afecções, imagens ou ideias, não são separáveis da duração que as relaciona ao estado precedente e as induzem ao estado seguinte. Essas durações ou variações contínuas de perfeição [posse da própria potência] são chamados afetos.
} 
a formação continuada e a experiência ética do corpo na produção do currículo da educação infantil

passar ao processo de produção das relações educadoras? Que potencialidades estes afetos engendram para a concepção de novos modos de educar e ser professor?

A formação continuada se desdobraria dessa forma como tempo-espaço no qual os questionamentos se impõem e as certezas se abalam, abrindo-nos à um exercício liberador de exploração daquilo que, felizmente, não se pode planejar.

Somente no contexto desse espaço-tempo de produção do novo - na relação que se estabelece entre currículo da educação infantil e um processo formador aberto à experiência - que os conhecimentos instituídos, incluindo-se os saberes acadêmicos sobre a formação docente, poderão ganhar potencialmente sentidos renovadores.

\section{referências}

Brasil. Diretoria de Formação de Professores da Educação Básica. Relatório de gestão. Brasília, 2013

Disponível em: <https://www.capes.gov.br/images/stories/download/bolsas/1892014relatorio-PARFOR.pdf> Acesso em:

Deleuze, G. Diferença e Repetição. 2. ed. Rio de Janeiro: Graal, 2006.

Deleuze, Gilles. Conversações. São Paulo, SP: Brasiliense, 2005.

Deleuze, Gilles. Espinosa Filosofia Prática. São Paulo: Ed. 34, 1992.

Deleuze, Gilles. Diálogos. São Paulo: Escuta, 1998.

Deleuze, G. Platão e o Simulacro. In: Lógica do Sentido. Tradução de Luiz Roberto Salinas Fortes. São Paulo, Ed. Perspectivas, $1974.2^{\circ}$ Edição.

Deleuze, G. O abecedário de Gilles Deleuze: uma realização de Pierre-André Boutang, produzido pelas Éditions Montparnesse, Paris. 1988-1989. Disponível em: <www.ufrgs.br/corpoarteclinica/obra/abc.prn.pdf>. Acesso em: 18 jul. 2011.

Foucault, Michel. A hermenêutica do sujeito. São Paulo: Martins Fontes, 2004.

Foucault, Michel. A ética do cuidado de si como prática da liberdade. In: Ditos \& Escritos V Ética, Sexualidade, Política. Rio de Janeiro: Forense Universitária, 2004.

Larrosa, Jorge. Experiência e alteridade em educação. In: Experiencia y alteridade en educación. Org.: Skliar, Carlos e Larrosa, Jorge. Buenos Aires: Homo Sapiens Ediciones, 2009. Trad. Maria Carmem Silveira Barbosa e Susana Beatriz Fernandes

Lopes, Sammy W. Como criar para si um corpo aprendente? Ou, o que se passa entre o desejo, o pensamento e o tempo em uma educação para a potência. Tese de Doutorado. Universidade Federal do Espírito Santo, 2011.

Rolnik, Suely. Cartografia Sentimental Transformações Contemporâneas Do Desejo. Porto Alegre: Sulina, 2006.

recebido em: 02.02.2020

aprovado em: 30.05 .2020 